\title{
Formação docente: a experiência do pacto nacional pelo fortalecimento do ensino médio na Universidade Estadual de Ponta Grossa
}

\section{Teacher education: the experience of the national pact by strengthening the high school at the Universidade Estadual de Ponta Grossa}

\author{
Silvio Luiz Rutz da Silva \\ Universidade Estadual de Ponta Grossa - UEPG - Ponta Grossa - Brasil \\ rutz@uepg.br \\ Denise Puglia Zanon \\ Universidade Estadual de Ponta Grossa - UEPG - Ponta Grossa - Brasil \\ zanon pg@ig.com.br
}

\section{Resumo}

O curso de formação do Pacto Nacional pelo Fortalecimento do Ensino Médio (PNEM) foi desenvolvido em escolas de Ensino Médio, com a finalidade de desenvolver atividades de estudos e de troca de experiências sendo composto de atividades coletivas e individuais, organizadas em um conjunto de temas fundamentados nas Diretrizes Curriculares Nacionais para o Ensino Médio (DCNEM), para subsidiar a formação continuada do professor. As temáticas foram trabalhadas, de forma individual, por meio de leituras e exercícios práticos dirigidos e, de forma coletiva, em encontros semanais com duração de quatro horas, utilizando-se da hora-atividade. As atividades coletivas foram desenvolvidas com base em materiais, previamente produzidos pela equipe de consultores do Ensino Médio Inovador. O objetivo do curso de formação do PNEM foi possibilitar a compreensão das DCNEM, criando um espaço para a reflexão coletiva acerca da prática docente. $\mathrm{O}$ PNEM criou um espaço para a participação de todos os atores do processo educativo na reescrita do Projeto Político Pedagógico da escola (PPP) permitindo uma reflexão sobre o Trabalho Pedagógico do Professor.

Palavras-chave: Formação docente; Diretrizes; Reflexão Coletiva.

\begin{abstract}
The course of the national pact for strengthening high school (PNEM) was developed in high schools, with the purpose of developing studies and activities of exchange of experiences being composed of individual and collective activities, organized into a set of themes based on the National curriculum guidelines for high school (DCNEM), to support the continuing education of the teacher. The themes were worked, individually, through readings and exercises directed and, collectively, in weekly meetings with duration of 4 hours, using the time-activity. Collective activities were developed based on materials, previously produced by the consulting team of high school. The objective of the training course the PNEM was enable the understanding of DCNEM, creating a space for collective reflection about the teaching practice. The PNEM created a space for the participation of all actors of the educational process in the rewrite of the school
\end{abstract}


Pedagogical political project (PPP) allowing a reflection about the pedagogical work of the teacher.

Keywords: Teacher education; Guidelines; Collective Reflection.

\section{Introdução}

O Pacto Nacional pelo Fortalecimento do Ensino Médio (PNEM) é um programa de formação de professores pelo qual o Ministério da Educação e as secretarias estaduais e distrital de educação assumem o compromisso pela valorização da formação continuada dos professores e coordenadores pedagógicos que atuam no ensino médio público, nas áreas rurais e urbanas. (MEC, 2016; DA SILVA; ZANON, 2016). O PNEM foi instituído pela Portaria $\mathrm{n}$ - 1.140, de 22 de novembro de 2013, e representa a articulação e a coordenação de ações e estratégias entre a União e os governos estaduais e distrital na formulação e implantação de políticas para elevar o padrão de qualidade do Ensino Médio brasileiro, em suas diferentes modalidades, orientado pela perspectiva de inclusão de todos que a ele tem direito (MEC, 2016a; DA SILVA; ZANON, 2016).

Em um primeiro momento duas ações estratégicas estão articuladas, o redesenho curricular, em desenvolvimento nas escolas por meio do Programa Ensino Médio Inovador (ProEMI) e a Formação Continuada de professores do Ensino Médio, que iniciou no primeiro semestre de $2014 \mathrm{com}$ a execução da primeira etapa (MEC, 2016a). O desenho da formação continuada no contexto do PNEM expressa as discussões realizadas nos últimos anos pelo Ministério da Educação - MEC, Secretarias de Estado da Educação, Conselho Nacional dos Secretários Estaduais da Educação (CONSED), Universidades, Conselho Nacional de Educação e Movimentos Sociais, assim como as intensas discussões realizadas no Fórum de Coordenadores Estaduais do Ensino Médio.

Neste sentido, expressa o amadurecimento do país com vistas ao compromisso com uma Educação Básica plena (da Educação Infantil ao Ensino Médio) como direito de todos. Assim, ele é constituído principalmente pela articulação de ações existentes do MEC, Universidades Públicas e Secretarias de Educação estaduais e distrital, e de novas proposições de ações que passam a constituir-se num conjunto orgânico e definidor da política para o Ensino Médio brasileiro (MEC, 2016a; DA SILVA; ZANON, 2016).

O curso de formação do PNEM foi desenvolvido em escolas de Ensino Médio, que realizaram a inscrição dos professores com a finalidade de desenvolver atividades de estudos e de troca de experiências. Esse processo foi mediado pelo Orientador de Estudo. As temáticas foram trabalhadas, de forma individual, por meio de leituras e exercícios práticos dirigidos e, de forma coletiva, em encontros semanais com duração de quatro horas, utilizando-se a hora-atividade.

As atividades coletivas foram desenvolvidas com base em materiais, previamente produzidos pela equipe de consultores do Ensino Médio Inovador, disponibilizados aos participantes em tablets ou para download. O curso foi composto de atividades coletivas e individuais, organizadas em um conjunto de temas fundamentados nas DCNEM, para subsidiar a formação continuada do professor.

O objetivo do curso de formação do PNEM foi possibilitar a compreensão das DCNEM, criando um espaço para a reflexão coletiva acerca da prática docente e da importância da participação de todos os atores do processo educativo na reescrita do Projeto Político Pedagógico da escola (PPP), de modo que possam nortear o redesenho do currículo do Ensino Médio. Essas etapas contemplaram a abordagem dos seguintes campos temáticos: Sujeitos do Ensino Médio e Formação Humana Integral, Ensino Médio, Currículo, Organização e Gestão do Trabalho Pedagógico, Avaliação, Áreas de Conhecimento e Integração Curricular, Organização do Trabalho Pedagógico no Ensino Médio, Ciências Humanas, Ciências da Natureza, Linguagens e Matemática. 
Estas ações visaram, também, a melhoria da qualidade da educação e a implantação das Diretrizes Curriculares Nacionais para o Ensino Médio, documento que aponta o trabalho, a cultura, a ciência e a tecnologia como dimensões que devem estar contempladas nos currículos do Ensino Médio, que deverão integrar os conhecimentos das diferentes áreas que compõem o currículo (MEC, 2016a; DA SILVA; ZANON, 2016).

\section{Metodologia}

No estado do Paraná (Brasil) participam do PNEM em parceria com o MEC a Secretaria Estadual de Educação (SEED-PR) e nove Instituições públicas de Ensino Superior: Universidade Estadual de Londrina (UEL), Universidade Estadual de Maringá (UEM), Universidade Estadual de Ponta Grossa (UEPG), Universidade Estadual do Centro- Oeste (UNICENTRO), Universidade Estadual do Oeste do Paraná (UNIOESTE), Universidade Estadual do Norte Pioneiro (UENP), Universidade Estadual do Paraná (UNESPAR), Universidade Federal do Paraná (UFPR) e Universidade Tecnológica Federal do Paraná (UTFPR).

O curso de formação proposto pelo PNEM foi presencial e teve duração de dois anos e foi desenvolvido em duas etapas, com 100 horas cada uma, com a realização de encontros semanais. A formação continuada é uma das ações que compõem o PNEM, cujos objetivos são: promover melhoria da qualidade do Ensino Médio; ampliar os espaços de formação de todos os profissionais envolvidos nesta etapa da educação básica; desencadear um movimento de reflexão sobre as práticas curriculares que se desenvolvem nas escolas; e fomentar o desenvolvimento de práticas educativas efetivas com foco na formação humana integral, conforme apontado nas Diretrizes Curriculares Nacionais para o Ensino Médio (DA SILVA; ZANON, 2016).

O processo formativo apresentou como eixo estruturante a temática "Sujeitos do Ensino Médio e Formação Humana Integral" e este foi o fio condutor para a discussão e o trabalho em todas as etapas do curso. A duas etapas foram compostas pela formação comum a todos os participantes organizada nos núcleos: Ensino Médio e Formação Humana Integral; O Jovem como Sujeito do Ensino Médio; O currículo do Ensino Médio, seus Sujeitos e o Desafio da Formação Humana Integral; Áreas de Conhecimento e Integração Curricular; Organização e Gestão Democrática da Escola; e Avaliação no Ensino Médio. Para cada um dos cadernos do professor nas duas etapas várias atividades são propostas e que são detalhadas nos parágrafos seguintes. Os Cadernos de Formação do Professor podem ser acessados no link: $<$ http://pactoensinomedio.mec.gov.br/index.php?option=com_content\&view=category \&id $=13 \&$ Itemid $=117>$.

Os conteúdos, trabalhados em cada caderno foram selecionados e organizados em material didático específico composto por Cadernos Temáticos elaborados por Universidades parceiras do Programa de Formação Continuada de professores do Ensino Médio. Em cada um destes cadernos uma série de atividades foram propostas (DA SILVA; ZANON, 2016).

\section{Resultados}

A equipe do PNEM-UEPG nas duas etapas foi composta por: um coordenador, um coordenador adjunto, dois supervisores, quinze formadores da IES, quatro formadores regionais, cento e trinta e três orientadores de estudos, setenta e quatro coordenadores pedagógicos e um mil duzentos e noventa e quatro professores. Em sua área de abrangência, figura 1, o PNEM envolveu um total de 117 escolas dos Núcleos Regionais de Educação de Ponta Grossa, de Telêmaco Borba e de Wenceslau Braz com 1501 concluintes na primeira etapa, dois quais 1318 concluíram a segunda etapa. $\mathrm{Na}$ 
sequência apresentamos a caracterização dos participantes do PNEM (DA SILVA; ZANON, 2016).

Figura 1 - Área de abrangência da formação

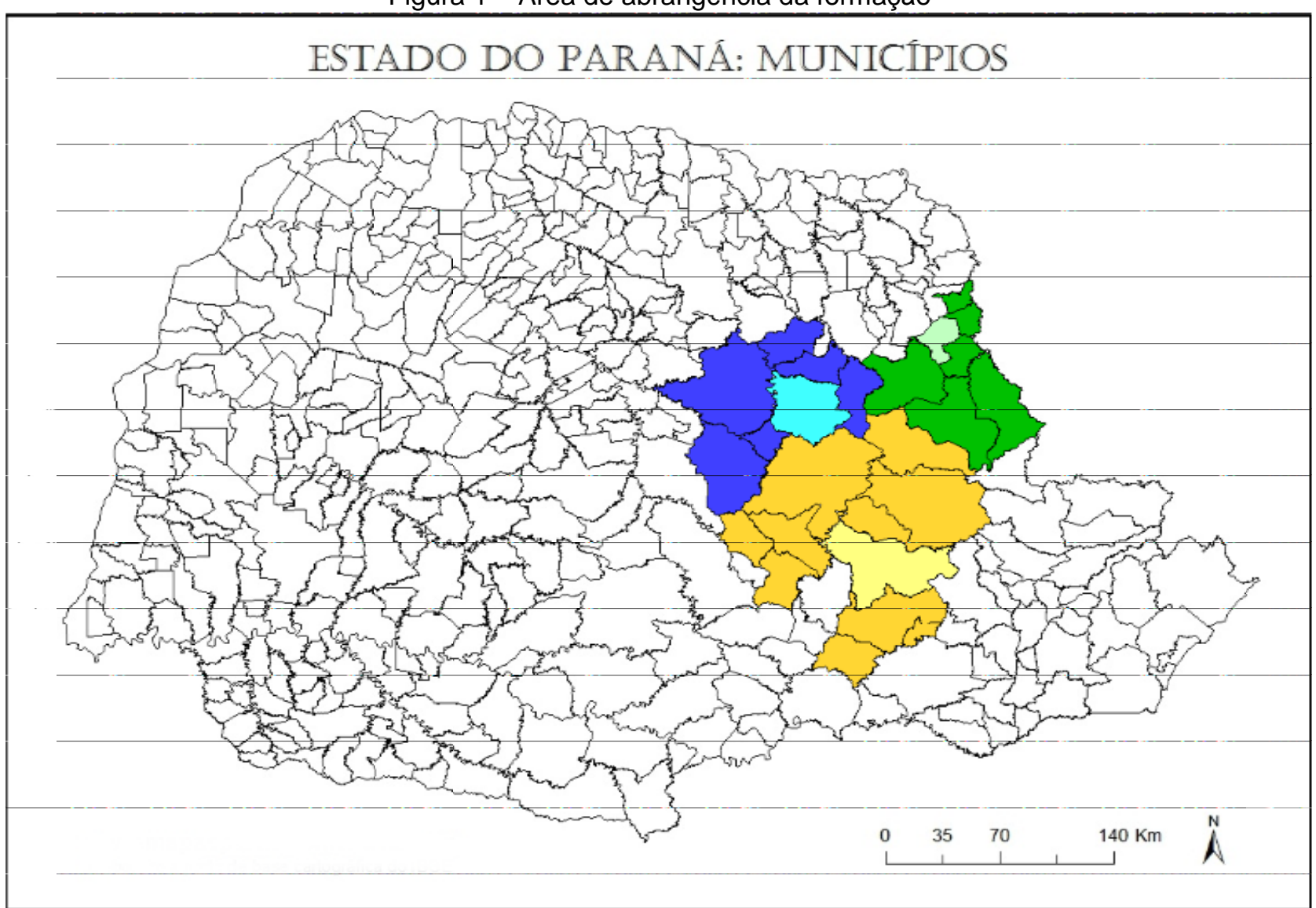

Fonte: Autoria própria (2016).

Inicialmente apresenta-se alguns dados do grupo relacionados a: faixa etária, gênero e formação acadêmica envolvendo a graduação e a pós-graduação. $O$ perfil de faixa etária, mostra que a maioria está na faixa de 30 a $50 \mathrm{com}$ um total de $65,45 \%$. Na faixa de 19 a 30 anos temos $16,09 \%$ dos cursistas e na faixa de 50 a 60 ou mais temos 18,47 dos cursistas (DA SILVA; ZANON, 2016).

O perfil de gênero dos cursistas que mostra que $72,85 \%$ são do gênero feminino e $27,15 \%$ masculino. A formação acadêmica, graduação, onde observa-se que a formação é bastante variada, com participantes com formação em licenciatura e também com bacharelados. Pedagogia, letras, matemática, história, geografia, educação física e ciências biológicas são os cursos com maior número de participantes, correspondendo a $67,51 \%$. Os outros $32,49 \%$ envolvem outros cursos de formação superior de licenciatura e bacharelado. Quanto à formação acadêmica destaca-se o número significativo de cursistas com especialização $(68,31 \%)$ e com mestrado e doutorado (5,89 \%) (DA SILVA; ZANON, 2016).

Inicialmente precedeu-se a formação dos orientadores de estudo e dos formadores regionais (figura 2). Nesta formação foram discutidos os textos de referência que compõem os cadernos de formação. Os orientadores de estudo e os formadores regionais receberam orientação a respeito dos mecanismos de planejamento, execução e acompanhamento dos estudos que foram realizados na unidade escolar como processo de formação individual e coletiva. Esta formação contou com um momento inicial presencial, na região da escola e, mais três encontros regionais para aprofundamento teórico, acompanhamento e avaliação da formação. A formação e o acompanhamento 
dos trabalhos dos orientadores de estudo e dos formadores regionais foram realizados pelo professor formador da IES (DA SILVA; ZANON, 2016).

$\mathrm{Na}$ sequência os orientadores de estudo organizaram suas turmas nas escolas para a execução do curso de formação (figura 2). As atividades do curso foram organizadas em dois momentos distintos: o primeiro momento foi composto por atividades individuais, onde o cursista organizou seu próprio tempo institucional para a leitura dos textos básicos do curso. O cursista deveria apresentar registros das reflexões realizadas durante suas leituras nas discussões com o grupo da escola (DA SILVA; ZANON, 2016).

Figura 2 - Encontros de formação dos formadores regionais e de formação dos cursistas nas escolas.
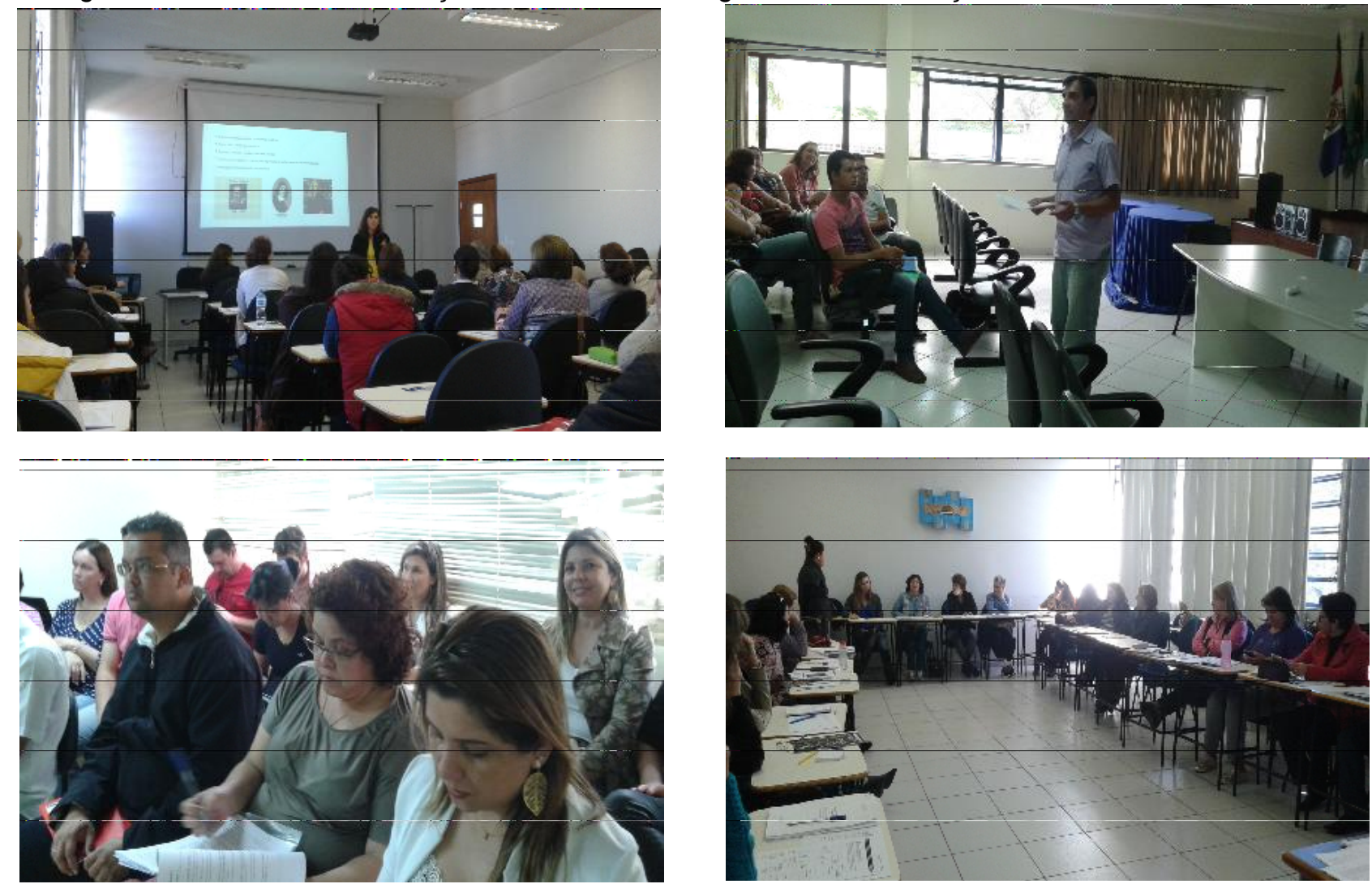

Fonte: Autoria própria (2016).

Ainda como parte das atividades individuais, o cursista deveria realizar (pelo menos) uma das atividades propostas no material de estudo no contexto de sala de aula. Todo processo foi orientado e acompanhado pelo orientador de estudo. $O$ segundo momento foi composto por atividades coletivas onde o grupo realizou estudos das DCNEM, dos textos sobre os campos temáticos e dos textos sobre as áreas de conhecimento e seus componentes curriculares. O orientador de estudo organizou em cada escola a proposta de formação, de acordo com a organização do trabalho pedagógico da escola, seus tempos e espaços institucionais, assim como as possibilidades de rearranjos da hora-atividade, de forma a privilegiar o trabalho coletivo (DA SILVA; ZANON, 2016).

Os cursos foram presenciais e as atividades coletivas realizadas na escola, durante a hora-atividade. Para o desenvolvimento dos processos formativos, a metodologia a ser adotada deveria proporcionar a reflexão sobre a prática educativa da escola, da constituição histórica de seus sujeitos na diversidade do ambiente social e escolar, bem como a análise, a sistematização e o registro de experiências. Dessa forma, a discussão das temáticas, a leitura de textos, a interface dos conteúdos com a realidade das escolas, seus professores e estudantes, a criação de espaços virtuais para socialização das 
experiências e os questionamentos e registros dos processos vivenciados deveriam estar presentes durante todo o processo (DA SILVA; ZANON, 2016).

No Caderno I da I ETAPA (figura 3) - Ensino Médio e Formação Humana Integral as atividades propostas foram (BRASIL; 2013): identificar os principais desafios do Ensino Médio no Brasil (p.26); traçar o perfil social, cultural e econômico dos sujeitos matriculados no Ensino Médio na escola (p.31); identificar os principais princípios e fundamentos que constituem a proposta de formação humana integral (p.40); e propor ações para o alcance da universalização do Ensino Médio (p.45).

Figura 3 - Caderno I da I ETAPA - Ensino Médio e Formação Humana Integral

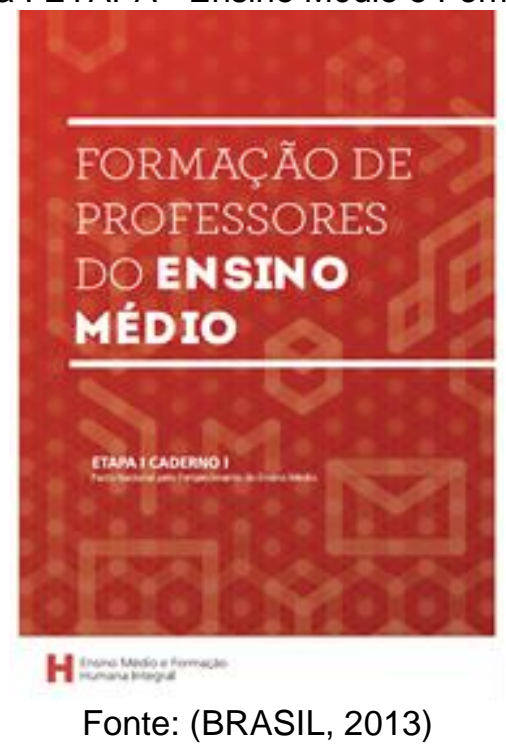

No Caderno II da I ETAPA (figura 4) - O Jovem como Sujeito do Ensino Médio (BRASIL, 2013a) as atividades propostas foram: refletir sobre os sentidos de estar na escola para professores e jovens (p.16); promover diálogo com os estudantes na escola sobre culturas juvenis (p.29); propor estratégias metodológicas para o diálogo com os jovens trabalhadores sobre suas expectativas e condições de trabalho (p.43); e redigir carta endereçada aos jovens estudantes do Ensino Médio (p.60).

Figura 4 - Caderno II da I ETAPA - O Jovem como Sujeito do Ensino Médio

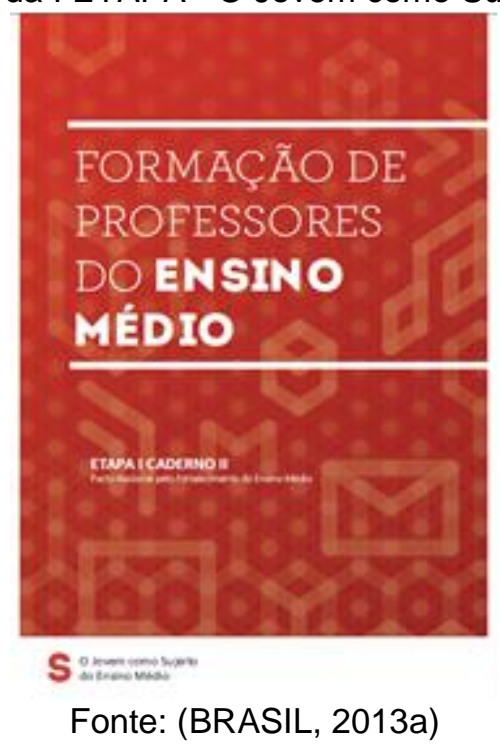

Para o Caderno III da I ETAPA (figura 5) - O Currículo do Ensino Médio (BRASIL, 2013b), seus sujeitos e o desafio da formação humana integral as atividades foram: 
debater com os professores na escola a relação entre os conteúdos ensinados, o mundo do trabalho, o da ciência, o da tecnologia e o da cultura (p.17); ler e discutir as Diretrizes Curriculares Nacionais do Ensino Médio com os professores da escola (p.27); redigir texto sobre as contribuições do que é ensinado na escola para o desenvolvimento da autonomia intelectual dos estudantes (p.34); debater com estudantes e professores do Ensino Médio o currículo da escola (p.44).

Figura 5 - Caderno III da I ETAPA - O Currículo do Ensino Médio

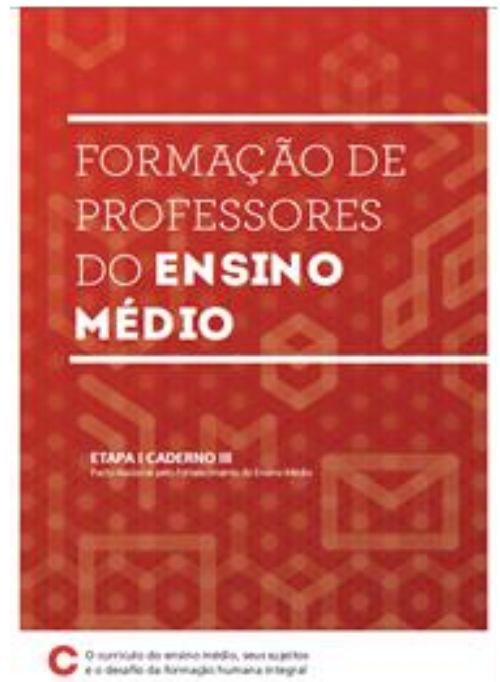

Fonte: (BRASIL, 2013b)

Para o Caderno IV da I ETAPA (figura 6) - Áreas de conhecimento e integração curricular (BRASIL, 2013c) as atividades foram: elaborar proposta de trabalho da temática "Educação alimentar e nutricional" em uma perspectiva integradora (p. 16); elaborar proposta de atividade (p.26); elaborar proposta curricular integrada (p.37); e analisar filme e reportagem e propor atividade em sala de aula (p.45).

Figura 6 - Caderno IV da I ETAPA - Áreas de Conhecimento e Integração Curricular.

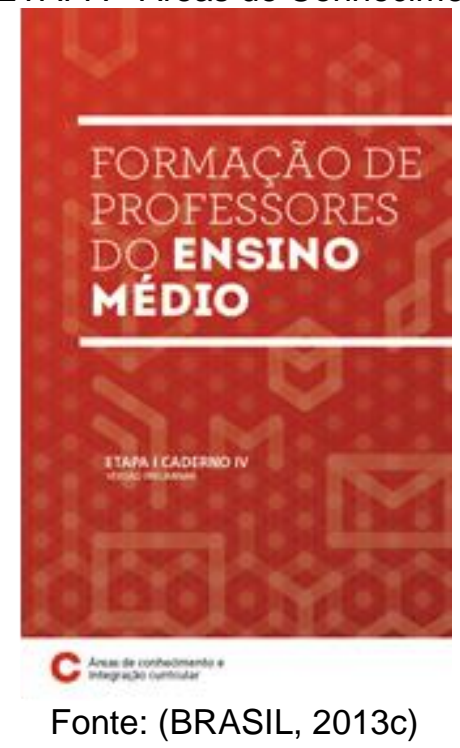

No Caderno V da I ETAPA (figura 7) - Organização e Gestão Democrática da Escola (BRASIL, 2013d) as atividades foram: debater a participação docente na gestão democrática da escola (p. 12); promover debate sobre situações vividas na escola que podem ser objeto de decisões coletivas (p.18); ler normas elaboradas pela Secretaria de Educação ou pelo Conselho de Educação do Estado sobre a instalação e o 
funcionamento dos Conselhos Escolares e verificar as decisões do Conselho Escolar instalado na escola (p.23); pesquisar a atuação do Grêmio Estudantil na escola (p.29); discutir e registrar experiências relativas à participação dos pais na vida escolar (p.38); e pesquisar o processo de elaboração do PPP da escola, analisar seu conteúdo e refletir sobre o ambiente em sala de aula, postura docente e estratégias de ensino (p.47).

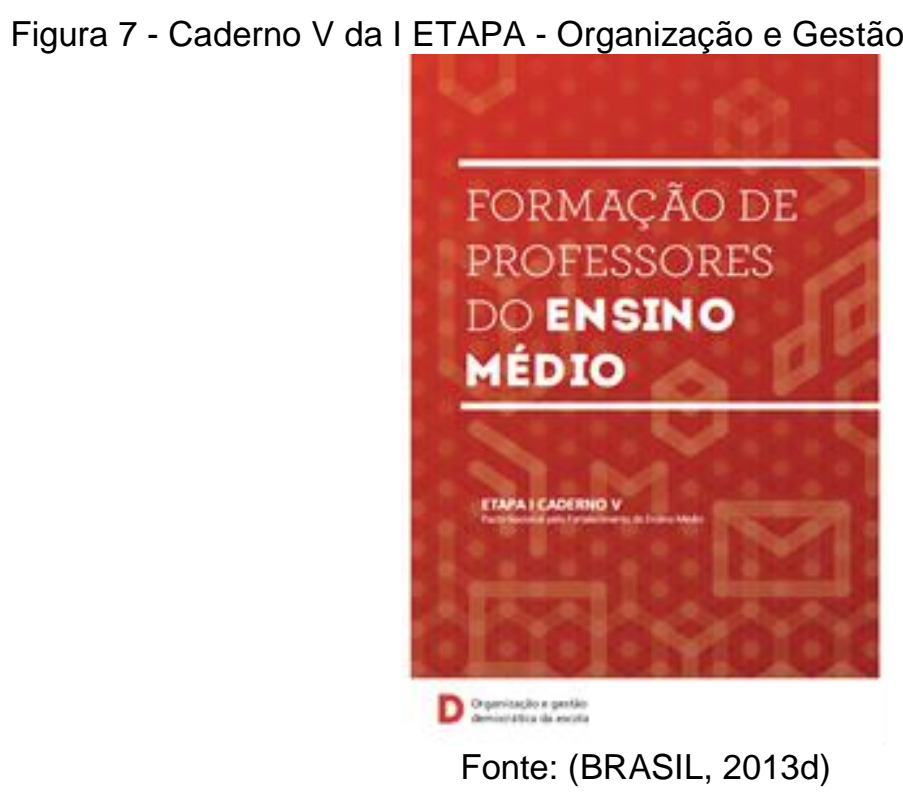

No Caderno VI da I ETAPA (figura 8) - Avaliação no Ensino Médio (BRASIL, 2013e) as atividades foram: discutir concepções de avaliação e os principais desafios no campo da avaliação educacional (p.17); analisar o projeto político-pedagógico e planos de ensino da escola para identificação de concepções de avaliação da aprendizagem, instrumentos e procedimentos de avaliação mais utilizados na escola, critérios de atribuição de notas e de aprovação (p. 28); coletar dados como a taxa de rendimento da escola e refletir sobre a avaliação da aprendizagem (p.38); e refletir sobre as avaliações educacionais externas e sobre a utilização de seus resultados (p. 50).

Figura 8 - Caderno VI da I ETAPA - Avaliação no Ensino Médio.

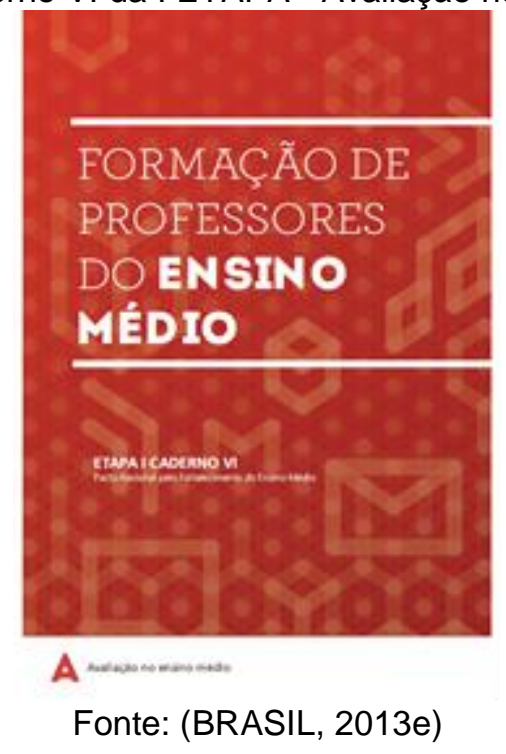

No Caderno I da II ETAPA (figura 9) - Organização do Trabalho Pedagógico no Ensino Médio (BRASIL, 2014) as atividades foram: refletir sobre a diversidade e a pluralidade na organização do trabalho pedagógico escolar (p.13-14); refletir acerca dos 
espaços de participação ampliada de estudantes, professores, funcionários e familiares nos processos de gestão democrática da escola (p.20); refletir sobre os elementos referenciais para a organização do trabalho pedagógico no Ensino Médio (p.32); refletir sobre a participação dos professores, coordenadores pedagógicos e gestores escolares na organização do trabalho pedagógico (p.40).

Figura 9 - Caderno I da II ETAPA - Organização do Trabalho Pedagógico no Ensino Médio.

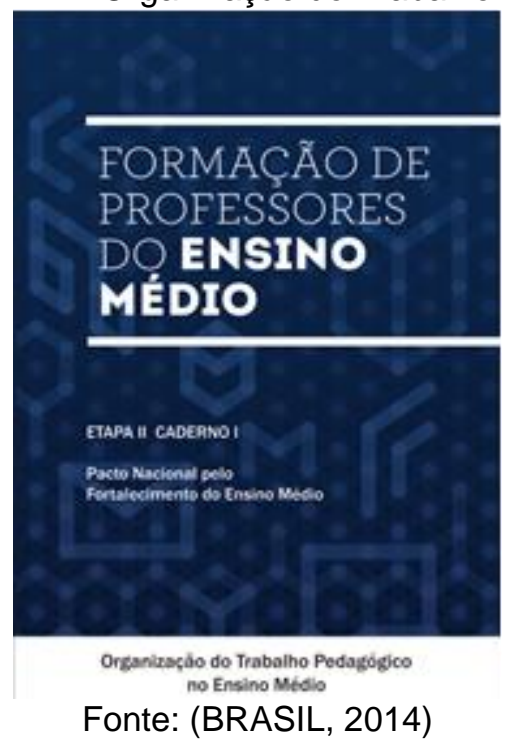

No Caderno II da II ETAPA (figura 10) - Ciências Humanas (BRASIL, 2014a) as atividades foram: desenvolver atividade com os alunos tendo por base o processo de humanização, buscando identificar quais são seus valores atuais, seus planos para o futuro (p.27-28); planejar uma ação curricular que considere a realidade específica dos estudantes em uma abordagem interdisciplinar entre diferentes componentes curriculares (p.36); planejar e realizar uma investigação científica (p.44-45).

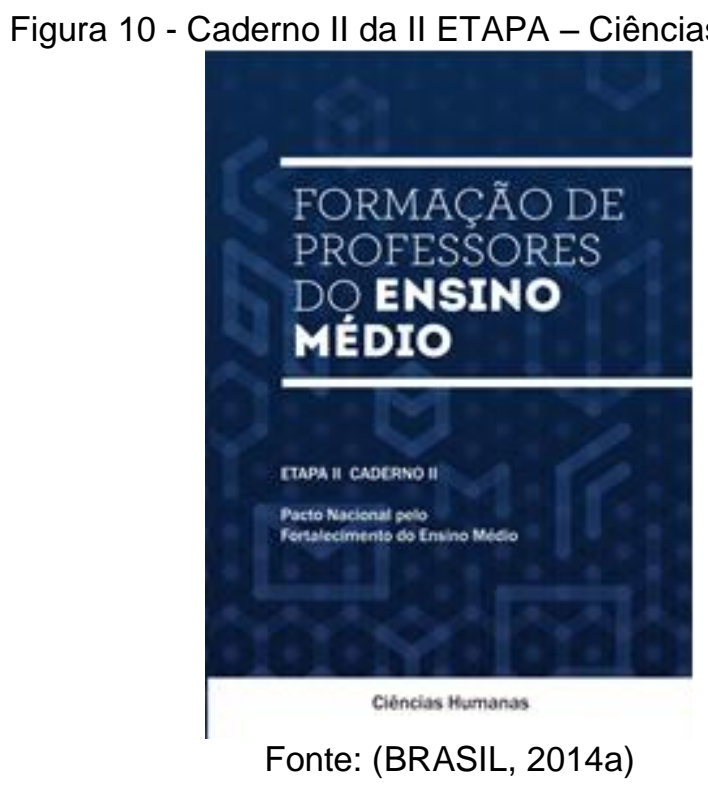

No Caderno III da II ETAPA (figura 11) - Ciências Naturais (BRASIL, 2014b) as atividades foram: realizar uma discussão sobre ciência e a forma como a mesma se materializa nos currículos e cotidianos das escolas (p.15); refletir sobre "ensinar ciências é" e "ensinar ciências não é", frente à concepção de que devemos estimular os estudantes a refletir, estabelecer relações entre os conhecimentos, a perceber que a 
ciência está em qualquer lugar, em qualquer fenômeno, seja ele natural ou social (p.21). Pensar no planejamento de uma atividade ou sequência de atividades de ensino desenvolvida de forma interdisciplinar (p.28); planejar uma unidade de ensino envolvendo os componentes curriculares da área de maneira interdisciplinar (p.42).

Figura 11 - Caderno III da II ETAPA - Ciências Naturais.

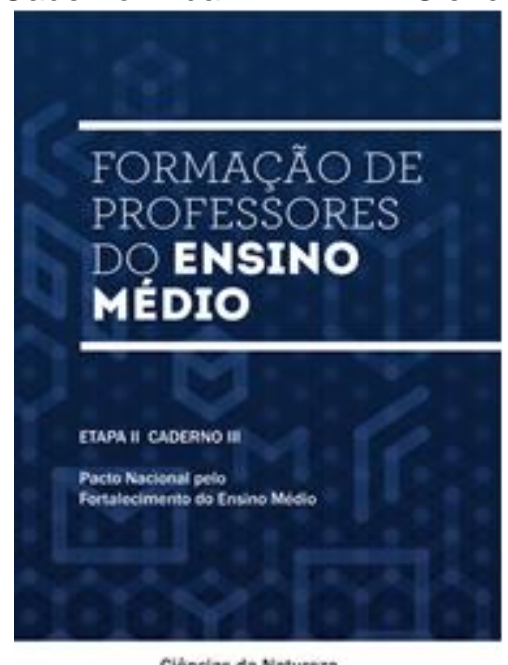

Fonte: (BRASIL, 2014b)

No Caderno IV da II ETAPA (figura 12) - Linguagens (BRASIL, 2014c) as atividades foram: discutir a formação da área de Linguagens, o conceito de linguagem e apresentar os conhecimentos da área (p.14); investigar formas de levar essas reflexões para a atividade educativa (p.21); planejar um trabalho interdisciplinar, em que linguagens e as diferentes dimensões do currículo: trabalho, cultura, ciência e tecnologia apareçam entrelaçados com um tema de interesse dos jovens de Ensino Médio (p.31); discutir as implicações dessas ideias para o seu componente curricular, abordando as técnicas mais usadas articulando as práticas, as ideias, pensamentos e valores que as norteiam (p.41).

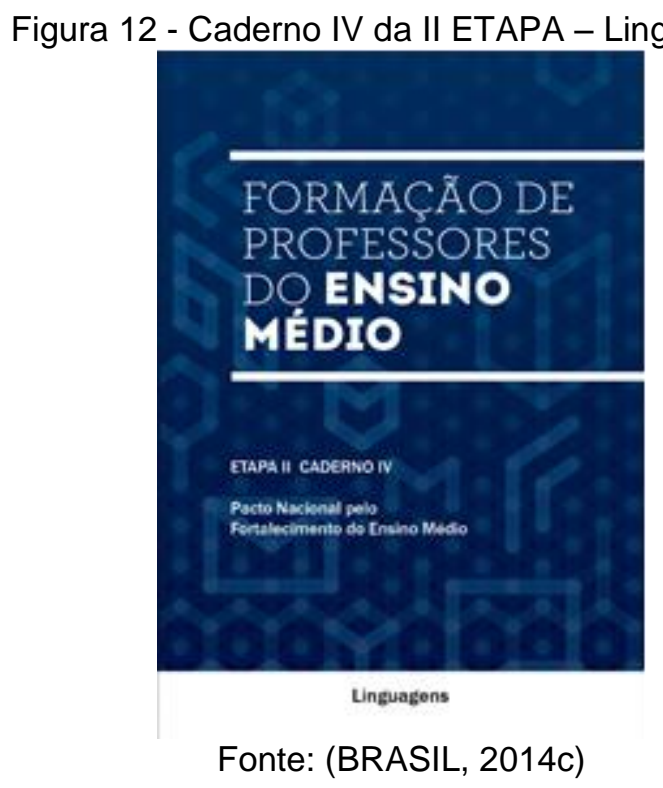

No Caderno V da II ETAPA (figura 13) - Matemática (BRASIL, 2014d) as atividades foram: identificar os tipos de pensamento matemático de modo a se obter maior equilíbrio em relação aos diversos tipos de pensamento matemático (p.14); construir um projeto que possa sustentar um trabalho coletivo dos estudantes e uma interação entre os diversos 
componentes curriculares (p.23); definir alguns critérios para a modificação de determinadas rotinas no trabalho que permitissem novos planejamentos mais integrados (p.31); organizar conjuntamente as ideias registrando as questões motivadoras, os objetivos e as ações pretendidas (p.39); formular um projeto de pesquisa e intervenção que possa mobilizar conhecimentos da área e com potencial de adesão dos estudantes à proposta. (p.42).

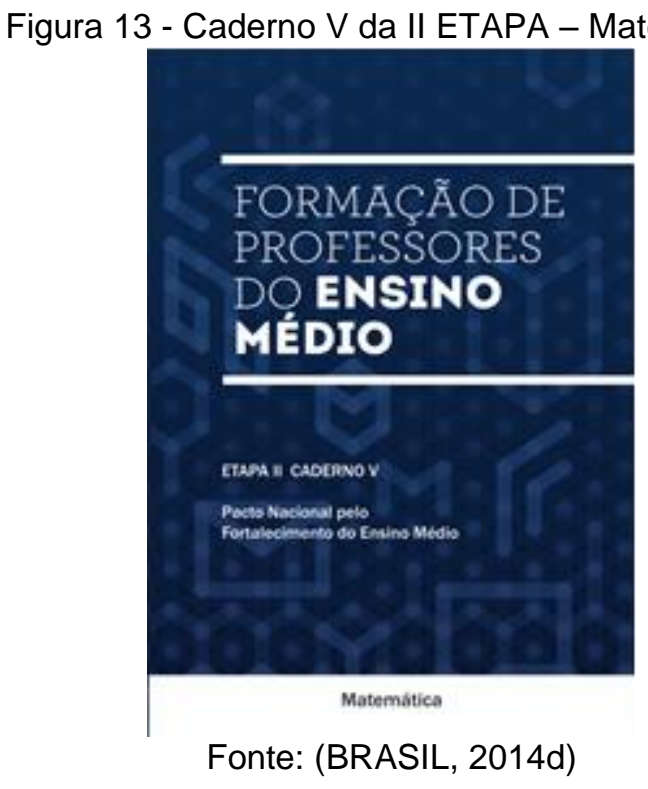

\section{Considerações finais}

A proposta do PNEM para o curso de formação dos professores do Ensino Médio compreende o professor como um sujeito epistêmico, que elabora e produz conhecimentos com base na compreensão da realidade e nas possibilidades de transformação da sociedade. Essa formação adquire relevância na medida em que propicia uma reflexão articulada à fundamentação teórica e à prática docente. Dada a dimensão da política de formação, quer pelo número de professores formados, quer pela diversidade do país, ou, ainda, pela complexidade dos problemas do próprio Ensino Médio, é necessário um processo articulado entre todos os entes, instituições e sujeitos responsáveis pela formação dos profissionais da educação.

Em suas duas etapas o PNEM apresentou um conjunto de temas fundamentados nas DCNEM, para subsidiar a formação continuada do professor cujo objetivo foi possibilitar a compreensão das DCNEM, criando um espaço para a reflexão coletiva acerca da prática docente e da importância da participação de todos os atores do processo educativo na escola.

\section{Referências}

BRASIL (2013). Secretaria de Educação Básica. Formação de professores do ensino médio, etapa I - caderno I: ensino médio e formação humana integral / Ministério da Educação, Secretaria de Educação Básica; [autores: Carmen Sylvia Vidigal Moraes... et al.]. - Curitiba: UFPR/Setor de Educação, 2013. 51p.

BRASIL (2013a). Secretaria de Educação Básica. Formação de professores do ensino médio, etapa I - caderno II: o jovem como sujeito do ensino médio / Ministério da 
Educação, Secretaria de Educação Básica; [organizadores: Paulo Carrano, Juarez Dayrell]. - Curitiba: UFPR/Setor de Educação, 2013. 69p.

BRASIL (2013b). Secretaria de Educação Básica. Formação de professores do ensino médio, etapa I - caderno III: o currículo do ensino médio, seu sujeito e o desafio da formação humana integral / Ministério da Educação, Secretaria de Educação Básica; [autores: Carlos Artexes Simões, Monica Ribeiro da Silva]. - Curitiba: UFPR/Setor de Educação, 2013. 49p.

BRASIL (2013c). Secretaria de Educação Básica. Formação de professores do ensino médio, etapa I - caderno IV: áreas de conhecimento e integração curricular / Ministério da Educação, Secretaria de Educação Básica; [autores: Marise Nogueira Ramos, Denise de Freitas, Alice Helena Campos Pierson]. - Curitiba: UFPR/Setor de Educação, 2013. 47p.

BRASIL (2013d). Secretaria de Educação Básica. Formação de professores do ensino médio, etapa I - caderno V: organização e gestão democrática da escola / Ministério da Educação, Secretaria de Educação Básica; [autores: Celso João Ferretti, Ronaldo Lima Araújo, Domingos Leite Lima Filho]. - Curitiba: UFPR/Setor de Educação, 2013. 53p.

BRASIL (2013e). Secretaria de Educação Básica. Formação de professores do ensino médio, etapa I - caderno VI: avaliação no ensino médio / Ministério da Educação, Secretaria de Educação Básica; [autores: Ocimar Alavarse, Gabriel Gabrowski]. Curitiba: UFPR/Setor de Educação, 2013. 58p.

BRASIL (2014). Secretaria de Educação Básica. Formação de professores do ensino médio, Etapa II - Caderno I: organização do trabalho pedagógico no ensino médio / Ministério da Educação, Secretaria de Educação Básica; [autores: Erisevelton Silva Lima et al.]. - Curitiba: UFPR/Setor de Educação, 2014. 49p.

BRASIL (2014a). Secretaria de Educação Básica. Formação de professores do ensino médio, Etapa II - Caderno II: ciências humanas / Ministério da Educação, Secretaria de Educação Básica; [autores: Alexandro Dantas Trindade et al.] - Curitiba: UFPR/Setor de Educação, 2014. 53p.

BRASIL (2014b). Secretaria de Educação Básica. Formação de professores do ensino médio, Etapa II - Caderno III: Ciências da Natureza / Ministério da Educação, Secretaria de Educação Básica; [autores: Daniela Lopes Scarpa et al.] - Curitiba: UFPR/Setor de Educação, 2014. 48p.

BRASIL (2014c). Secretaria de Educação Básica. Formação de professores do ensino médio, Etapa II - Caderno IV: Linguagens / Ministério da Educação, Secretaria de Educação Básica; [autores: Adair Bonini et al.]. - Curitiba: UFPR/Setor de Educação, 2014. 47p. 
BRASIL (2014d). Secretaria de Educação Básica. Formação de professores do ensino médio, Etapa II - Caderno V: Matemática / Ministério da Educação, Secretaria de Educação Básica; [autores: Ana Paula Jahn et al.] - Curitiba: UFPR/Setor de Educação, 2014. 49p.

DA SILVA, S. L. R.; ZANON, D. P. Formação docente interdisciplinar como espaço de reflexão coletiva acerca da prática docente. Revista de la Facultad de Ciencia y Tecnologia, Bogotá, v. Ell, p. 757 - 763, 2016.

MEC (2016). Pacto Nacional pelo Fortalecimento do Ensino Médio. Disponível em: $<$ http://portal.mec.gov.br/index.php?option=com_content\&id=20189\&ltemid=811> Acesso em: 1 out. 2016.

MEC (2016a). Pacto Nacional pelo Fortalecimento do Ensino Médio. Disponível em: < pactoensinomedio.mec.gov.br> Acesso em: 1 mai. 2015. 